\title{
Congenital Bronchial Atresia with a Calcified Mucocele
}

\author{
Elias Primetis Andreas Koureas Apostolos Dalakidis Thomas Prantzos \\ Konstantinos Palialexis Gouliamos Athanasios
}

Radiology Department, Aretaieio Hospital, University of Athens, Athens, Greece

A 31-year-old female was referred to our department to further evaluate an abnormal finding of a routine chest $\mathrm{X}$-ray. She had a 5 pack-year smoking history, no history of lower respiratory tract infection or other pulmonary disease, and no constitutional symptoms. Physical examination was unremarkable.

Chest X-ray (fig. 1) revealed a lobulated branching opacity with distal hyperinflation in the left upper lobe.
Chest CT confirmed the presence of a branching calcified lesion in the apicoposterior bronchus of the left upper lobe (fig. 2). Distal to the lesion, the lung parenchyma appeared hyperinflated with sparse vascularity. Imaging findings were consistent with congenital bronchial atresia with a calcified mucocele. Two years later, follow-up chest CT did not show any changes while the patient remained asymptomatic. Diagnosis of congeni-

Fig. 1. Chest X-ray revealed a lobulated branching opacity with distal hyperinflation in the left upper lobe.

Fig. 2. Chest CT confirmed the presence of a branching calcified lesion in the apicoposterior bronchus of the left upper lobe.

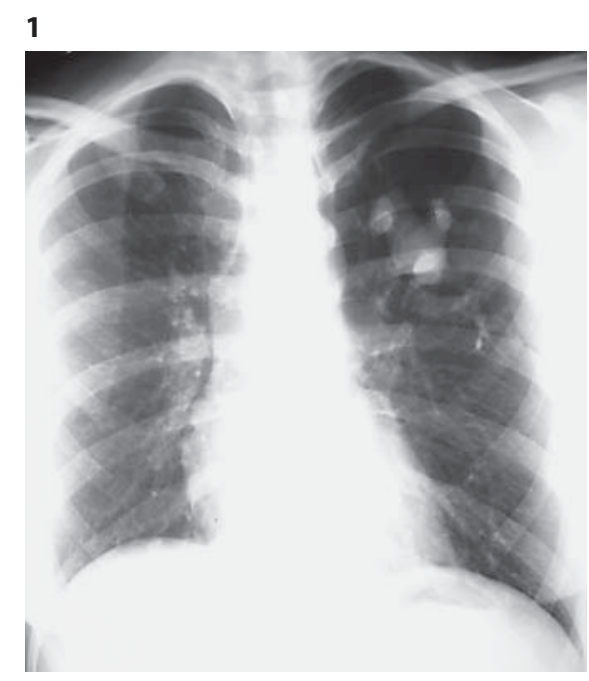

2

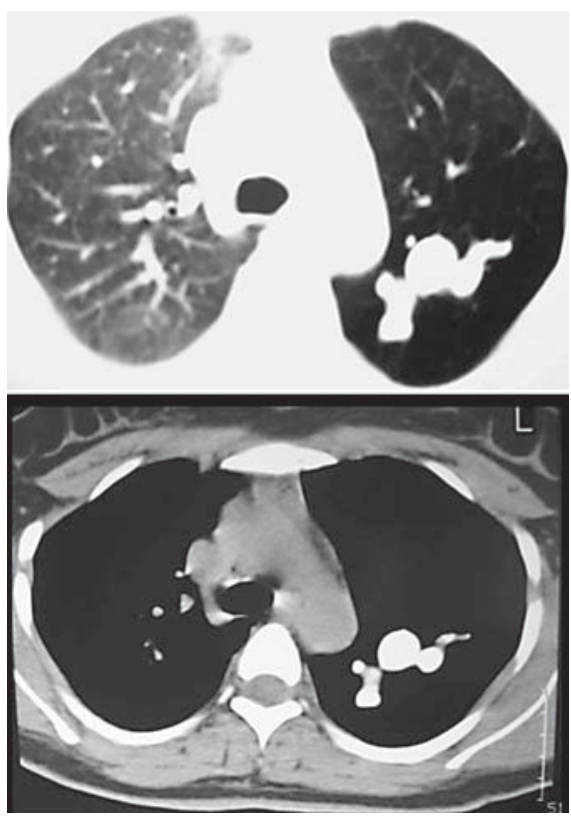

\section{KARGER}

Fax +4161306 1234

E-Mail karger@karger.ch

www.karger.com
(C) 2011 S. Karger AG, Basel

0025-7931/11/0816-0511\$38.00/0

Accessible online at:

www.karger.com/res
Dr. Apostolos Dalakidis

Aretaieio Hospital, University of Athens

Vas. Sofias Ave 76

GR-11528 Athens (Greece)

Tel. +30 210724 6103, E-Mail tolisroma@yahoo.com 
tal bronchial atresia with a calcified mucocele was established.

To our knowledge, a similar case of totally calcified mucocele in the context of congenital bronchial atresia has not been reported.

Bronchial atresia was first reported by Falor and Kyriakides in 1949. Its main pathogenetic event is an antenatal vascular insult of the fetal lung that results in an atresia of a lobe or segment and its respective airways [1]. Bronchoceles (or mucoceles) are subsequently formed due to retained secretions and mucous impactions. The lung distal to atresia can develop normally, but shows paucity

of blood vessels and is hyperinflated due to air flow through the pores of Kohn and canals of Lambert from adjacent normal lung [2].

References
1 Gipson MG, Cummings KW, Hurth KM: Best cases from the AFIP. Bronchial atresia. Radiographics 2009;2:1531-1535.

-2 Zylak CJ, Eyler WR, Spizarny DL, Stone CH: Developmental lung anomalies in the adult: radiologic-pathologic correlation. Radiographics 2002;22:S25-S43. 